\title{
NONINVASIVE VENTILATION IN CHILDREN
}

(C) by Acta Medica Saliniana ISSN 0350-364X

Type of manuscript: Professional papers

Title:

NONINVASIVE VENTILATION IN CHILDREN

Authors:

Devleta Hadžić ${ }^{1}$

DOI: $10.5457 / 488$

\section{Afiliations:}

${ }^{1}$ Clinic for Children's Diseases,

the University Clinical Center Tuzla

\section{Received:}

11.01.2019.

Corresponding author:

Devleta Hadžić

Email: devletahadzic@yahoo.com

The treatment of respiratory failure has seen progress since the early nineties. The development of noninvasive ventilation (NIV) provides new possibilities for better treatment and risk reduction. To achieve the therapeutic success of NIV and the reduction in incidence of complications, one must have knowledge of clinical indications and contraindications, the appropriate choice of ventilation modes and ventilation delivery equipment, close monitoring, and ventilation need to be started timely. The development of new technologies has expanded the indications for the use of NIV in children. Of particular importance is the clinical assessment of each patient, a good knowledge of the potential risks for failure of NIV, and creating a written local protocols for the NIV treatment in every health facility where this ventilation technique is applied.

Key words: noninvasive ventilation, respiratory failure, children.

\section{INTRODUCTION}

The treatment of respiratory failure has seen progress since the early nineties. Active research have boosted knowledge of the key pathophysiologic events in respiratory failure (1). Mechanical ventilation is a cornerstone in the management of patients with respiratory failure. A great progress has been made owing to today's modern computer technologies and new knowledge about mechanical ventilation. Technology of equipment required for mechanical ventilation is increasingly improving and meets the real needs of patients. Ventilation support can be invasive and noninvasive. Invasive mechanical ventilation is initially applied via endotracheal tube in pediatric intensive care unions, due to the need for sophisticated technologies and welleducated health professionals. In the case of prolonged mechanical ventilation, the tracheostomy tube needs to be established. The tracheostomy tube may also serve as a reliable support in home settings. It decreases sedation requirements, it is more comfortable in comparison to the endotracheal tube, it allows the use of voice, and sometimes allows easier separation from ventilation machine. The risks and adverse effects of mechanical ventilation are also well known (2). The development of noninvasive ventilation provides new opportunities for better treatment and risk reduction. Noninvasive mechanical ventilation of the lungs (NIV) is a form of respiratory support, i.e. ventilation that is established by delivering of positive pressure from mechanical ventilator to the patient's airways via the face or nose mask, as opposed to invasive mechanical ventilation that is established via the endotracheal tube or the tracheal cannula. The NIV technique is noninvasive only when it comes to the airway management. To achieve the therapeutic success of NIV and the reduction in incidence of complications, one must have knowledge of clinical indications and contraindications, the appropriate choice of ventilation modes and ventilation delivery equipment, close monitoring, and ventilation need to be started timely (3).

\section{History}

Some forms of mechanical ventilation can be identified even in the oldest written documents. The first experiments on animals in an attempt to achieve mechanical ventilation support are recorded in Europe during the Middle Ages. In 1559 Andreas Vesalius performed tracheotomies on his experimental animals and blew air into their lungs through a reed (4). Methodes of mechanical ventilation in humans have been in use since the beginning of the 20th century. It is believed that the first ventilator was invented by George E. Fill (Buffalo, New York), while Dröuger made them commercially available in 1907 (4). In the 1920s, a negative pressure ventilator, also known as "the iron lung" enabled a person to breathe on their own. In addition to medicine, the development of aviation enabled the further development of mechanical ventilation support. Namely, 
in 1940 Ray Benneth developed the portable device for oxygen delivery to an airplane pilots that was used during the WWII. Initially, respiratory failure was treated by mechanical ventilatory support in diseases with respiratory muscle weakness. At that time, those diseases were tetanus, polyomyelitis, botulism, neurological diseases and bacterial pneumonia, and later on those were meningitis, meningoencephalitis and sepsis. The first electric- powered ventilator called the iron lung was invented by Harvard medical researchers Philip Drinker and Louis Agassiz Shaw and installed at Bellevue hospital in New York City in 1927. The first patients of the iron lung were polio sufferers with chest paralysis (4). In effect, the devices for noninvasive ventilation developed first, but the main drawback of these interfaces is the difficulty to maintain quality care, physiotherapy, and there were a great risk of aspiration and regurgitation in addition to the preserved reflexes, as well as skin damage caused by the armor. Noninvasive mechanical ventilation became widely used during the poliomyelitis epidemics in the 1952, when the foundation and basic princiles of modern mechanical ventilation were set up, and when the importance of protection and controll of airways, the need for humidifying of the inspiratory gases and avoiding the high concentration of inhaled oxygen were much better understood (4). With this, noninvasive mechanical ventilation falls into oblivion until the beginning of the eighties of the last century when it begins to be used in the treatment of patients with obstructive sleep apnea. Interest in the use of noninvasive ventilation in the treatment of respiratory failure of different etiologies has markedly increased during the last three decades. Over the years, the use of noninvasive ventilation have also shown an increase in pediatric patients.

\section{The advantages of noninvasive mechanical ventilation}

Numerous studies indicate benefits of NIV compared to conventional mechanical ventilation. The use of NIV reduces the number of complications associated with intubation and the incidence of pneumonia caused by ventilator. It also reduces nosocomial infections and adverse effects of sedation in intubated patients. Patients who receive noninvasive ventilation stay shorter in intensive care union, have less number of hospital days and lower mortality rate. Intermittent use of NIV allows patients to communicate and to take adequate nutrition/ liquids, and medication orally, which all speaks in favour of patient comfor. Besides, NIV can be applied at different levels of care, in the intensive care union, the semi- intensive care union, standard hospial departments, the hospital admission unit, but also it is suitable for home settings (5).

\section{Noninvasive ventilation indications}

The NIV can be applied in respiratory failure caused by acute exacerbation of chronic obstructive pulmonary disease, neuromuscular diseases, acute cardiogenic pulmonary edema, in immunocompromised patients, postoperative respiratory failure, after extubation, in patients with diffuse pneumonia who are hypoxic even all other therapeutic measures are being applied. The main indication in children is chronic respiratory failure and sleep apnea (6).

\section{Respiratory failure in children}

Respiratory failure is a disorder of the main function of the lungs, gas exchange function: oxigenation and carbon dioxide elimination resulting in hypoxemia and hypercapnia. Respiratory failure may be acute and chronic depending on the rate of formation and duration of pathological process . Respiratory failure is determined by ABG parameters of the partial pressure of oxygen in arterial blood below $8 \mathrm{kPa}$ and by the partial pressure of carbon dioxide in arterial blood above $6 \mathrm{kPa}$ (7-10). Formally and from aspects of respiratory failure, the respiratory system is divided into two parts. The first part is consisted of the lungs with main role for the exchange of oxygen and carbon dioxide gasses, and the second part is a ventilation pump consisted of a chest wall, respiratory muscle, neuromuscular transmission, peripheral and spinal nerves and respiratory center. In general, respiratory failure happens when the lungs fails in gas exchange function, because of the lung diseases, leading to hypoxemia with normocapnia or hypocapnia, which is designated as Type 1 respiratory failure or hypoxemic type that can be treated with oxygen therapy. The ventilation pump failure results in alveolar hypoventilation and hypercapnia, which is designated as Type 2 respiratory failure or hypercapnic type that can be treated with some forms of vetilation support. Hypoxemia follows both types of respiratory failure. However, Type 2 respiratory failure is characterized and distinguished by elevated partial pressure of carbon dioxide in arterial blood (7). Since respiration as one of the basic vital functions is being conditioned by mutual interaction of several organs and organic systems, respiratory failure can be the result of several different pathological conditions and diseases. Some of the most common causes of respiratory failure in children with underlying organic disorder are listed in Table 1. 
Table 1. The most common causes of respiratory failure in children

\begin{tabular}{|l|l|}
\hline Neurological disorders & $\begin{array}{l}\text { epilepsy status, } \\
\text { meningoencephalitis, } \\
\text { tumors, abscesses, } \\
\text { bleeding }\end{array}$ \\
\hline Neuromuscular disorders & $\begin{array}{l}\text { myasthenia, myopathy, } \\
\text { neuropathy }\end{array}$ \\
\hline Obstruction of the upper respiratory tract & $\begin{array}{l}\text { epiglotitis, } \\
\text { laryngotracheitis, } \\
\text { tracheomalacia }\end{array}$ \\
\hline Obstruction of the lower respiratory tract & $\begin{array}{l}\text { Aspiration of a foreign } \\
\text { body, asthma, } \\
\text { bronchomalation, deficit } \\
\text { ólantitrips }\end{array}$ \\
\hline Pulmonary disorders & $\begin{array}{l}\text { pneumonia, cystic } \\
\text { fibrosis, tuberculosis, } \\
\text { pulmonary edema }\end{array}$ \\
\hline Other causes & $\begin{array}{l}\text { Heart diseases, anemia, } \\
\text { poisoning, anaphylaxis }\end{array}$ \\
\hline
\end{tabular}

As a rule, infants and young children develop acute respiratory failure much easier and faster than older children and adults, thus reflecting certain physiological and anatomical characteristics of the youngest population. A patient with respiratory problems develops a clinical picture of the so-called respiratory distress with a number of symptoms and signs that can be patogenetically grouped: signs of increased breathing, signs of compensatory mechanisms exhaustion, signs of poor breathing efficiency and other symptoms and signs (7). Clinical symptomatology of respiratory failure is shown in Table 2.

Table 2. Clinical signs of acute respiratory failure

\begin{tabular}{|l|l|}
\hline Respiratory & Cardiology \\
\hline $\begin{array}{l}\text { tachipnea } \\
\text { difficult inspiration, "air catching" } \\
\text { disturbed depth and breathing pattern (deep, shallow, } \\
\text { apnea, irregular, abdominal) } \\
\text { retraction of the chest wall } \\
\text { fluttering nostrils } \\
\text { cyanosis } \\
\text { weakened or absent breathing sound } \\
\text { expiratory moaning } \\
\text { wheezing and/or prolonged expirium }\end{array}$ & $\begin{array}{l}\text { tachycardia } \\
\text { hypertension } \\
\text { bradycardia } \\
\text { hypotension } \\
\text { cardiac arrest }\end{array}$ \\
\hline Gastrointenstinal & \\
\hline $\begin{array}{l}\text { increase in liver enzymes } \\
\text { bleeding from the gastrointenstinal tract }\end{array}$ & \\
\hline
\end{tabular}

Breathnig disorders are usually obvious and depending on severity they can be even dramatic. However, the essential for a clinician is the method of respiratory failure assessing: that could be used to separate risky children before respiratory failure, and by virtue of we could use the best mode of ventilator support, treatment and monitoring. The assessment and diagnosis must take into account all aspects of respiratory function, its effects to other organs and systems, but also to assess the capacity and reserves of the child to deal with breathing difficulties, which is also the hardest part for objectivisation. A one- time assessment of breathing is important, but much more clinically relevant information is obtained by frequent and systematic monitoring of patient with aim to determine the trend of changes in his condition. That is particulary important in the assessment of respiration in the lowes age groups in which due to a number of physiological and anatomical reasons there is no possibility of longterm compensation. For that reason the newborns and infants have fast switch from the stage of dyspnoea to the phase of acute respiratory failure, and that would be the most common cause of cardiac arrest in children (7). For the assessment of alveolar ventilation an arterial blood gas test is used because their partial pressure is approximately the same as in the pulmonary capillary blood. Pediatric practice has demonstrated the reliability of a capillary blood sample that can be taken from the ear or fingertip. (10). The finding of blood gases in certain forms of respiratory failure is shown in Table 3. 
Table 3. Types and characteristics of respiratory failure (RF) in children

\begin{tabular}{|l|c|l|c|}
\hline Type RF & p02 & pCO2 & pH \\
\hline Hypoxemic & $\downarrow$ & Normal/ & \\
\hline Hypercapnic & $\downarrow$ & $\uparrow$ & \\
\hline Acute & $\downarrow$ & $\uparrow$ & $\downarrow$ \\
\hline Chronic & $\downarrow$ & $\uparrow$ & Normal \\
\hline Exacerbation & $\downarrow$ & $\uparrow$ & $\downarrow$ \\
\hline $\begin{array}{l}\text { RF - respiratory failure; P02- partial pressure of oxygen; } \\
\text { PCO2- partial pressure of carbon dioxide; HCO3- bicarbonate }\end{array}$ \\
\hline
\end{tabular}

\section{Contraindications for NIV}

Contraindications for clinical application of NIV are shown in Table 4. Some authors divide contraindications to absulte and relative ones.

Table 4. Noninvasive ventilation (NIV) in children

Indications
- Hypoxic or hypercapnic respiratory failure in hemodinamically stable children
- Bronchiolitis
- Asthma status
- Pneumonia
- Cystic fibrosis
- Obstruction of upper respiratory tract (laryngeal and tracheomalacia, Pierre Robin Sy.)
- Chest syndrome (sicle cells anemia)

Of particular importance is the clinical assesment of each patient, a good knowledge of the potential risks for failure of NIV, and creating a written local protocols for the NIV treatment in every health facility where this ventilation technique is applied (11).

\section{NIV modes}

The choice of the appropriate NIV mode is of the greatest importance for improving of clinical status of patients in whom this type of ventilator support is applied. Applaying the appropriate mode reduces respiratory activity and dyspnea, and improves gas exchange in the lung. NIV can be achieved through standard mechanical ventilators, which are used in intensive care unions and portable ventilators, which are designed exclusively for NIV. The choice of the type of ventilators depends on the experience of a clinicians, the condition of the patient, the therapeutic requirements and the place where NIV is applied. It should be kept in mind that devices which are used in intensive care unions do not have operating options to correct potential losses if they occur, while small portable devices which are exclusively designed for NIV have that option thanks to the microprocessor recording the difference between inspiratory and expiratory volume (12).

\section{Continuous Positive Airway Pressure - CPAP}

Continuous Positive Airway Pressure- CPAP was introduced in clinical practice in the 1980s and it is the simplest mode of NIV. CPAP is delivered to patients via nose, mouth or face mask that is connected with an expiratory valve. During the CPAP application, the airway pressure is maintained continuosly (in inspirium and expirium) above the atmospheric value, which allows the alveoli to open in inspirium, and at the same time it prevents its collapse in expiriumthe final result is hypoxemiia correction. Therefore, the CPAP application improves oxygenation, reduces respiratory activity and hypoxia, as well as it reduces intrapulmonary shunt (13).

\section{Biphasic Positive Airway Pressure - BiPAP}

Biphasic Positive Airway Pressure -BiPAP ( Bilevel Positive Airway Pressure) was introduced in clinical practice in 1989. Positive pressure during ventilation is achieved at two different levels, upper and lower: during inspirium (the inspiratory positive airway pressureIPAP) and expirium (the expiratory positive airway pressure- EPAP or CPAP) The difference between the IPAP and EPAP is the pressure support of the lung ventilation. This mode of noninvasive ventilation help reduce the inspiratory work of breathing to a greater extent compared to CPAP (14).

\section{Non Invasive Pressure Support - NIVPS}

Non Invasive Pressure Support - NIVPS is a type of ventilation that is limited by pressure, and the patient triggers inspiratory flow while expiratory is passive. The patient controls inspiratory and expiratory times. Ventilator delivers previously set inspiratory pressure to 
assist spontaneous respiratory attempts of the patient. This type of ventilatory support works according to the protocol cycle, which means that expirium starts at the moment of drop in the protocol values below the values that were previously set on ventilator. NIVPS is thought to help the work of inspiratory muscles, effectivelly alleviate respiratory distress and reduce the work of breathing (15).

\section{Masks for NIV}

The choice of appropriate and comfortable equipment (interface) through this type of ventilation is delivered: nose mask, oronasal mask, full- face mask, helmet, nasal pillows and nose extensions are of great importance for the success of NIV. Each of these interfaces has specific features. The data collected in an online survey involving about 300 intensive care units and pulmonology departments across Europe has shown that the most common used interfaces in the treatment of respiratory failure are oronasal masks followed by nose masks, full- face masks and helmets (16). These interfaces can be found on the market in several sizes and shapes. The choice of an adequate interface for NIV is crucial for its overall success and for avoiding the most common complications (17). Therefore, prior to starting NIV it is important to devote sufficient time to choosing the appropriate mask for a particular patient and its adjustment. Nose masks are covering nose while oronasal masks are covering both nose and mouth. The most common mask- related complications are air leak, claustrophobia, facial skin erythema, skin damage, and eye irritation. Nasal masks have several advantages for patients compared to oronasal and full- face masks. They are allowing a patient to talk and cough, and are much better for patient who struggle with feelings of claustrophobia. Oronasal masks compared to nasal masks allow for more air loss, especially through the mouth, so longer adjustment of patient is neccessary. Because of this, oronasal masks are preferred in the initial treatment of acute respiratory failure. Nasal and oronasal masks make direct pressure on the nose ridge and can cause skin irritations and sores. To reduce the pressure, masks have gel or air filled pillows that increase comfort. However, the most important strategy in the prevention of pressure skin damage is correct mask positioning and adjusting. Mask should be attached to the head in such a way that two fingers can pass between the face and fixing tape. This allows the loss of a small amount of air from the system, which is acceptable and does not significantly affect the patient and ventilator interaction. The full-face masks can deliver greater pressure support, with smaller amount of air loss. They require less cooperation of patient and allow breathing through the mouth. However, they are less comfortable and prevent communication and nutrition through the mouth. A helmet consist of a cylinder that covers the head and the part or the entire neck.

\section{Monitoring during NIV application}

The appropriate monitoring is required for efficient and safe NIV application: patient's subjective condition, clinical parameters, ventilation parameters and gas exchange (18). Subjective parameters are: a patient's tolerance to the agent thorough which NIV is applied (interface), and his tolerance to the given type of ventilation and parameters. Clinical parameters related to patients that should be monitored are: state of consciousness, the chest movements, respiratory frequency, heart frequency, arterial blood presure, continuous ECG monitoring, accessory muscle use and paradoxical breathing. Ventilation parameters that should be followed: is there air leaking, is it pressure support adequate, is it PEEP adequate, is it respiratory volume $(5-7 \mathrm{ml} / \mathrm{kg})$ adequate, is there cooperation between the patient and ventilator. Monitoring of gas exchange includes continuous puls oximetry and arterial blood gas anayzes. Gas analyzes are taken at particular intervals of time, and mandatory prior to the begining of this type of ventilation, where the target value $\mathrm{SpO} 2$ is above $92 \%$.

When the therapeutic effects of NIV are not satisfactory, the main question is when mechanical ventilation of the lungs should be started? The indications for switching from NIV to invasive mechanical ventilation of the lungs are: lack of improvement of gas exchange, dyspnea maintenance, haemodynamic instability, deterioration of neurological condition of the patient, and when the patient does not tolerate NIV for any reason (18).

\section{NIV disadvantages}

One of disadvantages in the application of NIV is losses. Despite the alarms limits set on ventilator, in the case of a loss, the amount of air that ventilator delivers to the patient cannot be precisely determined. Air leaking may cause dryness of the cornea with the subsequent development of conjuctivitis. As a result of aerophagia, the stomach distension occurs, which increases the risk of gastric contents aspiration, as the respiratory tract is unprotected. Placing of a nasogastric tube solves the problem of the stomach distension, but not the problem of air leakage. Inadequate selection of interface potentially increase patients discomfort and cause the skin damage (19).

\section{The role of health professionals in NIV application}

The team work of doctors, respiratory physiotherapists and nurses is essential for a successful application of NIV. This type of respiratory support is time demanding. When starting NIV it is necessary to make the maximum effort in choosing an appropriate interface and its correct adjustion to a particular patient. Well- educated and experienced health care professionals should carefully monitor the patient to whom this type of mechanical ventilation support is applied. Particular attention should be paid not only to the vital signs and values of gas analysis, but also to the comfort and patient's tolerance of interface. Intubation equipment should be prepared in a case of inadequate response to start immediate invasive ventilation. It is very important for all team members to be wel- educated and competent about practical and technical aspects of NIV. Nurses should have knowledge and skills about proper fitting of interfaces, interpretation of displayed alarms, 
and monitoring and assessment of patient depending on the overall condition of patient. Respiratory therapists should be trained in an ongoing management of noninvasive ventilation, proper masks fitting, ventilator settings, verification and problems solving, as well as equipment maintenance. The success of the NIV increases with experience of the respiratory team.

\section{CONCLUSION}

NIV is one of several possible forms of ventilatory support in acute and chronic respiratory failure. Knowledge of clinical indications, contraidications, modes of ventilation and interfaces, respiratory monitoring and repetative training and presence of

\section{REFERENCES}

1. Mok YH, Lee JH, Rehder KJ, Turner DA. Adjunctive treatments in pediatric acute respiratory distress syndrome. Expert Rev Respir Med. 2014;8(6):703-16.

2. Conti G, Piastra M. Mechanical ventilation for children. Curr Opin Crit Care. 2016;22(1):60-6.

3. O'Boyle AL, Mink RB, Anas NG, Kallay TC. Development of learning objectives and a validated testing tool for management of pediatric mechanical ventilation*. Pediatr Crit Care Med. 2014;15(7):594-9.

4. Kacmarek RM. The mechanical ventilator: past, present, and future. Respir Care. 2011;56(8):1170-80.

5. Yaman A, Kendirli T, Ödek C, Ates C, Tasyapar N, Günes M, İnce E. Efficacy of noninvasive mechanical ventilation in prevention of intubation and reintubation in the pediatric intensive care unit. J Crit Care. 2016 Apr; 32: 175-81.

6. Morley SL. Non-invasive ventilation in paediatric critical care. Paediatr Respir Rev. 2016 Sep; 20: 24-31.

7. Richards AM. Pediatric Respiratory Emergencies. Emerg Med Clin North Am. 2016 Feb; 34(1): 77-96.

8. Graham RJ, Rodday AM, Weidner RA, Parsons SK. The Impact on Family of Pediatric Chronic Respiratory Failure in the Home. J Pediatr. 2016 Aug; 175: 40-6.

9. Akkermans R. Sedation in children with acute respiratory failure. Lancet Respir Med. 2015;3(3):184.

10. Sun B. The Focus of Treating Pediatric Acute Hypoxemic Respiratory Failure in Immunocompromised Patients. Pediatr Crit Care Med. 2016 Apr; 17(4): 363-4.

11. Blackwood B, Murray M, Chisakuta A, Cardwell CR, O'Halloran $P$. Protocolized versus non-protocolized weaning for all healthcare providers are therefore essential to the application of NIV. This is the only way to improve NIV efficiency, to avoid numerous complications during its application, and to prevent deteoriation of the general condition of the patient. Today, NIV is considered to be the first- line treatment for many chronic diseases that can be accompanied by respiratory failure. Given the well- documented positive effects of this form of treatment, any doctor involved in respiratory care of patients should be familiar with it. The access to patients need to be based upon his or her individual need, with respect to parents' rights for access to full and true medical information and records, but also the obligation to co-operate with the medical team caring for their child.

reducing the duration of invasive mechanical ventilation in critically ill paediatric patients. Cochrane Database Syst Rev. 2013;7:CD009082

12. Deden K. Ventilation modes in intensive care. Drager Medical GmbH Izdanje/Edition:1-2012.

13. Nathan AM, Loo HY, de Bruyne JA, Eg KP, Kee SY, Thavagnanam S, Bouniu M, Wong JE, Gan CS, Lum LC. Thirteen years of invasive and noninvasive home ventilation for children in a developing country: A retrospective study. Pediatr Pulmonol. 2017 Apr; 52(4): 500-507.

14. Pavone M, Verrillo E, Caldarelli V, Ullmann N, Cutrera R. Noninvasive positive pressure ventilation in children. Early Hum Dev. 2013 Oct; 89 Suppl 3: S25-31.

15. Grossbach I, Chlan L, Tracy MF. Overview of Mechanical Ventilatory Support and Management of Patient - and Ventilatory - Realated Responses, Crit Care Nurse 2011:31:3044

16. Majerić - Kogler V., Bošan Kilibarda I. Održavanje dišnog puta i mehanička ventilacija u izvanbolničkim uvjetima, Medicinska naklada, Zagreb, 2011.

17. Argent AC. Noninvasive Ventilatory Support: The Detail Lies in the Interface. Respir Care. 2015 Nov; 60(11): 1708-10.

18. Demaret $P$, Mulder A, Loeckx I, Trippaerts M, Lebrun F. Noninvasive ventilation is useful in paediatric intensive care units if children are appropriately selected and carefully monitored. Acta Paediatr. 2015 Sep; 104(9): 861-71.

19. Hull J. The value of non-invasive ventilation. Arch Dis Child. 2014 Nov; 99(11): 1050-4 